\title{
Open-celled silicon carbide foams with high porosity from boron-modified polycarbosilanes
}

\author{
Charlotte Durif ${ }^{a}$, Mélanie Wynn ${ }^{\mathrm{a}, \mathrm{b}, \mathrm{c}}$, Maxime Balestrat ${ }^{\mathrm{b}}$, Giorgia Franchin ${ }^{\mathrm{d}}$, Young-Wook Kim ${ }^{\mathrm{e}}$, \\ Anne Leriche $^{c}$, Philippe Miele ${ }^{a}$, Paolo Colombo ${ }^{d}$, Samuel Bernard ${ }^{b, \square}$ \\ a IEM (Institut Europeen des Membranes), UMR 5635 (CNRS-ENSCM-UM), Universite Montpellier, Place E. Bataillon, F- 34095, Montpellier, France \\ ${ }^{\mathrm{b}}$ Univ. Limoges, CNRS, IRCER, UMR 7315, F-87000, Limoges, France \\ ${ }^{\mathrm{c}}$ Univ. Polytechnique Hauts-de-France, EA2443 - Laboratoire des Matériaux Céramiques et Procédés Associés, F-59313 Valenciennes, France \\ ${ }^{\mathrm{d}}$ Dipartimento di Ingegneria Industriale, University of Padova, Padova, Italy \\ ${ }^{\mathrm{e}}$ Functional Ceramics Laboratory, Department of Materials Science and Engineering, The University of Seoul, Seoul 02504, Republic of Korea
}

Keywords:

Porous materials

Ceramic foams

Precursors

Preceramic polymers

Ceramic processing

\begin{abstract}
A B S T R A C T
Open-Celled silicon carbide $(\mathrm{SiC})$ foams were prepared from a mixture of a boron-modified polycarbosilane as a preceramic polymer and poly(methymetacrylate) (PMMA) microbeads as sacrificial agents. The process consists in the cross-linking of the liquid allylhydridopolycarbosilane (AHPCS, SiC precursor) with borane dimethylsulfide (BDMS, boron source) to form a solid boron-modified polycarbosilane with an adjusted crosslinking degree. The latter is mixed with PMMA microbeads $(25 \mu \mathrm{m})$ in a 20:80 ratio and the mixture is warmpressed at $120^{\circ} \mathrm{C}$ forming consolidated green bodies to be pyrolyzed at $1000^{\circ} \mathrm{C}$ under argon and to deliver opencelled SiC foams with an interconnected porosity of 73.4 vol\%. These foams combine a low density with a compressive strength of $3.49 \pm 0.56 \mathrm{MPa}$ and a thermal and mechanical stability under argon up to $1300{ }^{\circ} \mathrm{C}$. Ageing and microfiltration tests in the conditions of a primary loop of coolant in a Pressurized Water Reactor (PWR) showed that foams display a relatively high stability while retaining particles of $5 \mu \mathrm{m}$ in diameter making these materials as appropriate candidates to work in separation techniques under harsh environments.
\end{abstract}

\section{Introduction}

Porous solids possessing a large amount of internal surface area are suitable for performing specific functions for a large variety of applications related to separation techniques, i.e., especially for energy and environment-related fields, that require fast and effi cient transport in, out, or within a high porosity. Their performance and function are governed by the class of materials they belong to, i.e., polymers, metals, ceramics, the chemical composition of the considered porous scaff old material, and the porosity characteristics (pore shape, average pore size and size distribution, pore interconnectivity and tortuosity).

An appropriate classification of the porosity is based on the investigations made by Dubinin [1] and adopted by Everett [2] then Sing et al. [3]. It consists in classifying pores as macropores ( $>50 \mathrm{~nm}$, sintered ceramics, foams, ...), mesopores in the range of 2-50 nm (mesoporous silica and carbon, ...) and micropores $<2 \mathrm{~nm}$ (zeolite, activated carbon, metal organic framework, membranes, ...) [4]. In such systems, (large) macropores are ideal for providing easy access to internal sites, while micro- or mesopores increase the surface area and therefore improve selectivity $[5,6]$.

The development of porosity in ceramics extends the functionality of the latter toward applications where a defined permeability for various fluids is required, especially at high temperature [7]. A typical example is the Diesel Particulate Filter (DPF) usually made of silicon carbide ( $\mathrm{SiC}$ ), mainly used for the safe and eff ective reduction of Diesel engine exhaust gases and soot [8].

The porosity characteristics, thus the production of highly porous ceramic components such as $\mathrm{SiC}$, are all determined by the selected processing strategies. In particular, designing porosity from nanoscale to microscale is a unique attribute of the chemical material technologies. Among these technologies, the chemical approaches based on tailormade preceramic polymers, such as the polymer-derived cera- mics (PDCs) route, off er a precise control over chemical compositions, microstructure and porosity characteristics at diff erent length scales for ceramics.

The PDCs method is based on the synthesis of a preceramic polymer as a precursor [9-14]. Its main purpose is to produce ceramic components, often as non-oxide, through the thermo-chemical conversion of

\footnotetext{
${ }^{\square}$ Corresponding author.

E-mail address: samuel.bernard@unilim.fr (S. Bernard).
} 
preceramic polymers via shaping (to form the desired component), curing (to further crosslink the polymer), pyrolysis (to transform the cured polymer into an amorphous ceramic) and optionally annealing (to crystallize the amorphous ceramic). Interestingly, because of the possibilities of controlling the cross-linking degree, the type of bonds linking monomeric units and the nature of functional groups in preceramic polymers, polymer shaping (before or during curing) can be carried out to produce thin parts or complex architectures such as fibers, coatings, or dense monoliths [15-17]. If the PDCs route is coupled with a porous network design method, at the polymer level, a control of the porosity can be achieved at various length scales [18-22]. Based on the advantages provided by the PDCs route, the processing of opencelled SiC foams has been exploited in the present paper.

An approach to prepare open-celled foams consists in using sacrificial agents serving as placeholder substances to create open pore networks in the final ceramics [21-26]. Such agents mainly include organic materials that decompose without leaving residues during heating, such as poly(methyl methacrylate) (PMMA) beads, and that can be directly mixed with the SiC precursors. The selection of the latter is important: because uniaxial warm-pressing is a typical forming method to shape mixtures of preceramic polymers and PMMA and deliver highly porous non-oxide ceramics in monolithic form after pyrolysis [22,23], an ideal open-celled SiC foam precursor would display a relatively high crosslink degree to be processed into pellets by warmpressing while plastic deformation then precursor particle joining occur, leading to infusible and consolidated green bodies. Subsequent pyrolysis should retain the shape of the material (i.e., controlled volume shrinkage) and lead to open-celled PDC foams (if the PMMA beads mixed with the ceramic precursor before warm-pressing are embedded in an amount large enough to create an interconnecting network), through the conversion of the precursor into ceramics, while PMMA is removed to leave voids, i.e., macropores.

The pioneered commercially available polycarbosilane (PCS), nominally ' $\left[\mathrm{SiH}\left(\mathrm{CH}_{3}\right) \mathrm{CH}_{2}\right]_{n}$ ' obtained upon thermolysis of polysilanes (PS) $[27,28]$, is a solid preceramic polymer displaying a relatively high ratio of $\mathrm{C}$ to $\mathrm{Si}(2: 1)$ and a complex structure which appears to contain largely carbosilane linkages. PCS is melt-spinnable and led in the middle of the seventies to the achievement of the 1st generation of SiC fibers called Nicalon ${ }^{\mathrm{TM}}[27,28]$. However, the preparation of other geometries than fibers is diffi cult because of the low ceramic yield of PCS and the strong shrinkage occurring during its pyrolytic conversion. Moreover, the compositional purity of the SiC ceramic produced by this process is limited by the lack of cross-linking moieties in the precursor, which requires oxidative curing to generate a non-fusible polymeric body. As a second commercially available PCS precursor, allylhydridopolycarbosilane (AHPCS), nominally $\left[\mathrm{Si}\left(\mathrm{CH}_{2} \mathrm{CH}=\mathrm{CH}_{2}\right)\right.$ ) $\left.\mathrm{HCH}_{2}\right]_{0.1}\left[\mathrm{SiH}_{2} \mathrm{CH}_{2}\right]_{0.9}$ [29] is produced by the Starfire Systems company [30]. It is a liquid and can produce $\mathrm{SiC}$ with an almost stoichiometric C:Si ratio. It has been previously investigated to produce porous SiC through its combination with PE [26] and PMMA [31] microbeads. The latter reported the mixing of AHPCS and PMMA microbeads in a slurry to be casted and then pyrolysed at $900^{\circ} \mathrm{C}$, forming foams. As a proof of concept, a thick disc-shaped porous ceramic body was successfully produced using 68 vol $\%$ of PMMA beads ( $90 \mu \mathrm{m}$ diameter), after pyrolysis at $900^{\circ} \mathrm{C}$. No detailed information was provided about the morphological, mechanical and thermal characteristics of the materials. The major issue of AHPCS is its relatively low degree of crosslinking and the lack of low temperature cross-linkable functional groups, both involving the releases low molecular weight species such as oligomers in the early stages of the pyrolysis. This inherently reduces the ceramic yield while increasing the volume shrinkage, making the process diffi cult to scale up. Furthermore, using liquid AHPCS and solid sacrificial agents, it is really challenging to obtain highly porous components (porosity above 70 vol\%) with a high degree of pore interconnectivity.

For further processing AHPCS into open-celled SiC foams, a solution would consist in firstly cross-linking the liquid AHPCS, allowing its transformation into rigid solid-state materials that could be then homogeneously mixed with PMMA microbeads. Thus, the latter will exhibit a higher ceramic yield to form open-celled SiC foams with a reduced volume shrinkage. This strategy has been demonstrated to prepare dense SiC objects [32]. However, this requires relatively high cross-linking temperatures ( $\mathrm{T}$ approaching $250{ }^{\circ} \mathrm{C}$ ) and uniaxial warmpressing should be performed at a significant higher temperature $\left(T>250{ }^{\circ} \mathrm{C}\right)$. Furthermore, it is diffi cult to precisely control the crosslinking evolution via the temperature (and the time at the set temperature), and the resulting polymers can be extensively crosslinked and therefore no longer processible.

To form a solid-state $\mathrm{SiC}$ precursors with a tuned plasticity at relatively low temperature, we modified AHPCS with borane dimethylsulfide to synthesize a boron-modified AHPCS with a tailored cross-linking degree according to a strategy reported recently by our group on various types of commercially available preceramic polymers [33-37]. Thus, this strategy allowed us to produce open-celled SiC foams containing free carbon and a low boron content by warm- pressing and pyrolysis. Carbon and boron additives are often used as sintering aids during the densification of $\mathrm{SiC}$, based on the fact that carbon inhibits the ineff ective mass transport while boron favors dif- fusion and hence the ceramic densification [38]. Based on this strategy, we report, in the first part of the paper, the design of open-celled SiC foams by mixing the boron-modified AHPCS with PMMA microbeads of

$25 \mu \mathrm{m}$ in diameter. As-synthesized materials were characterized in detail by elemental analyses, SEM, mercury porosimetry and mechanical tests. To identify the potential of using these materials in harsh environments, their behavior at high temperature was investigated via HT-TGA, SEM, mercury porosimetry and BET. Then, aging as well as microfiltration tests were performed to simulate the conditions of a primary loop of coolant in a Pressurized Water Reactor (PWR). The schematic representation of the synthetic process is shown in Fig. 1.

\section{Experimental procedure}

For all the synthesis reactions, a ventilated hood equipped with a vacuum/argon line allowed to manipulate the chemical products under argon atmosphere. Argon ( $>99.995 \%$ ) was purified by passing through a column of phosphorus pentoxide (Sigma-Aldrich, Saint Quentin, France), sicapent ${ }^{\mathrm{TM}}$ (Millipore S.A.S, Molsheim, France) and copper oxide-based catalysts (Sigma-Aldrich, Saint Quentin, France)). The glassware was stored in an oven at $120^{\circ} \mathrm{C}$ overnight before being assembled and pumped under vacuum for $30 \mathrm{~min}$ and then filled with argon. In order to keep inert conditions after the synthesis reactions, the manipulation of the chemical products was made inside argon-filled glove boxes (MBraun MB200B; $\mathrm{O}_{2}$ and $\mathrm{H}_{2} \mathrm{O}$ concentrations kept at $<$ 0.1 ppm and Jacomex, Campus-type; $\mathrm{O}_{2}$ and $\mathrm{H}_{2} \mathrm{O}$ concentrations kept at $\leq 0.1 \mathrm{ppm}$ and $\leq 0.8 \mathrm{ppm}$, respectively). Allylhydridopolycarbosilane (AHPCS labeled SMP-10, Starfire Systems ${ }^{\circledR}$ Incorporation, New York, USA), with a density of $0.998 \mathrm{~g} . \mathrm{cm}^{-3}$, was used as-received. Toluene (99.85\%, Extra Dry over Molecular Sieve, AcroSeal(R)) was obtained from Acros Organics. Borane dimethylsulfide $\mathrm{BH}_{3} \cdot \mathrm{S}\left(\mathrm{CH}_{3}\right)_{2}$ (BDMS complex solution $2.0 \mathrm{M}$ in toluene) was obtained from Sigma Aldrich. Poly (methylmetacrylate) (PMMA) microbeads with a diameter of $25 \mu \mathrm{m}$ were provided by Atofina Italia, Milan, Italy.

\subsection{Material preparation}

Open-celled SiC foams were produced from a boron-modified allylhydridopolycarbosilane labelled AHPCSB30 (30 being the Si:B ratio fixed during the polymer synthesis) which was synthesized by reaction between AHPCS and BDMS according to a previously published report [33]. AHPCSB30 was ground in an agate mortar, then it was mixed with $25 \mu \mathrm{m}$ PMMA microbeads in AHPCSB30:PMMA weight ratios 


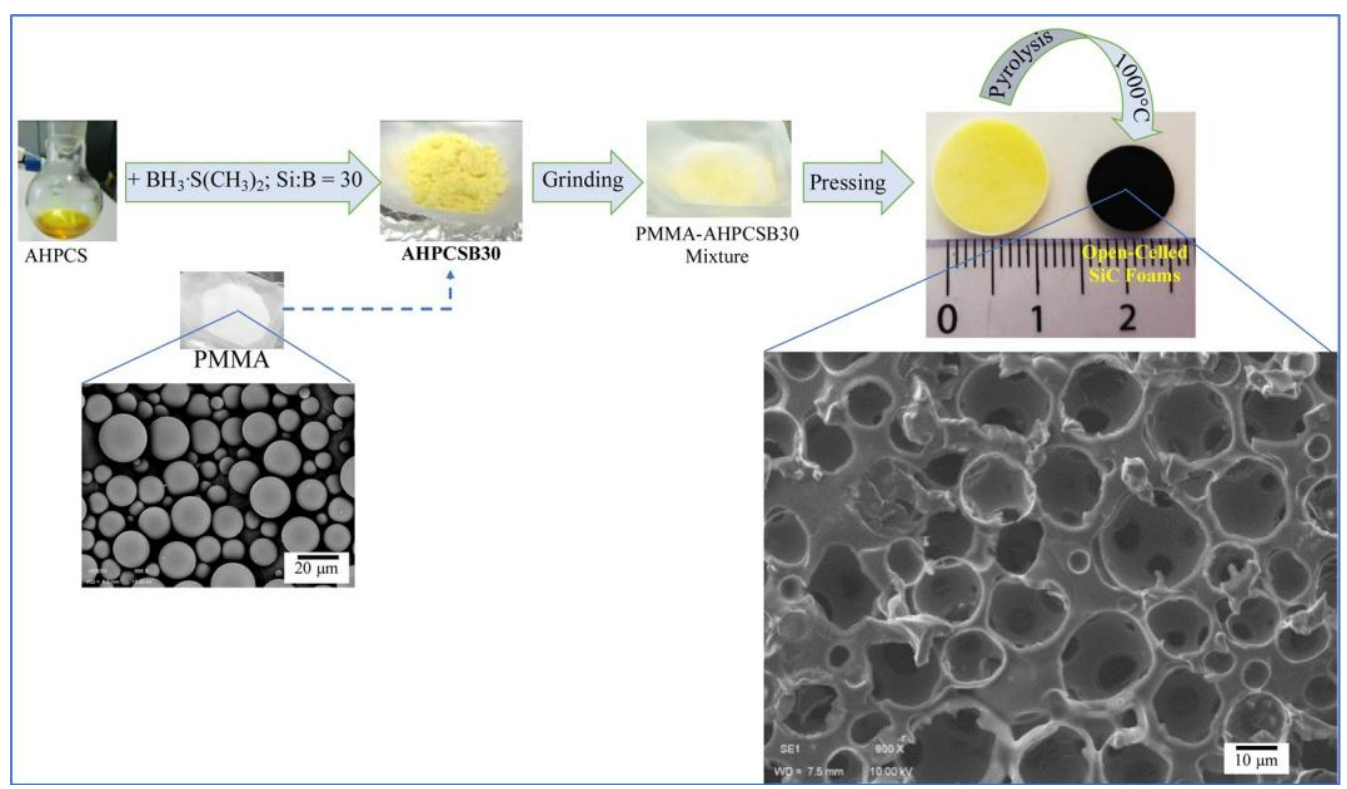

Fig. 1. Overall synthetic path employed to generate open-celled SiC foams from boron-modified AHPCS. High magnification SEM image of the mSiBC30_10 samples as inset.

ranging from 10:90 to 30:70. The mixture was homogenized in a mortar and the mixture was then pressed at $74 \mathrm{MPa}$, in a steel die with diameter $13 \mathrm{~mm}$ with a heating mantle, from RT to $120{ }^{\circ} \mathrm{C}$, using an automatic uniaxial press (Atlas Auto model, Specac) set-up in a nitrogenfilled glove-box. We also investigated a higher steel die diameter (25.6 $\mathrm{mm}$ ) for further scaling-up. The homogeneous mixture was in- troduced in the steel die, put under load and heated to the desired temperature of warm-pressing, then the temperature was held for $0.5 \mathrm{~h}$. The samples were slowly deloaded after cooling down to RT (within $1 \mathrm{~h}$ ). Typical dimensions of the cylindrical green bodies were $13 \mathrm{~mm} \times 1.6$ $\mathrm{mm}$ (Please note that compressive strength measurements required a sample thickness of $4 \mathrm{~mm}$; thus, we used a higher quantity of mixture for warm-pressing to perform mechanical measurements). Green samples were placed in alumina boats, and then transferred under argon flow into a silica tube inserted in a horizontal furnace (Carbolite BGHA12/450B). The tube was pumped under vacuum $\left(1.10^{-1} \mathrm{mbar}\right)$ and refilled with argon (99.995\%) at atmospheric pressure. Subsequently, the samples were subjected to a cycle of ramping of $0.5^{\circ} \mathrm{C} \cdot \mathrm{min}^{-1}$ to $450^{\circ} \mathrm{C}$ (dwelling time of $2 \mathrm{~h}$ ) then to $1000^{\circ} \mathrm{C}$ (dwelling time of $2 \mathrm{~h}$ ) to form mSiBC30_10 samples. A constant flow of argon $\left(120 \mathrm{~mL} \cdot \mathrm{min}^{-1}\right)$ was passed through the tube during the pyrolysis cycle. In order to investigate the high temperature behavior of the mSiBC30_10 samples, annealing treatments were performed above $1000{ }^{\circ} \mathrm{C}$ in a graphite furnace (Gero Model HTK 8). The furnace was pumped under vacuum $\left(1.10^{-1} \mathrm{mbar}\right)$, refilled with argon and maintained under a constant flow of argon $\left(200 \mathrm{~mL} \cdot \mathrm{min}^{-1}\right)$ during the whole heat treatment. The program consisted of a $5^{\circ} \mathrm{C} \mathrm{min}^{-1}$ heating ramp up to the maximum temperature fixed in the range $1000-1500^{\circ} \mathrm{C}$, dwelling at this temperature for $2 \mathrm{~h}$, and cooling down to RT at $5{ }^{\circ} \mathrm{C} \cdot \mathrm{min}^{-1}$. The samples were labelled as $\mathrm{mSiBC} 30 \_\mathrm{X}, \mathrm{X}$ being the two first digits of the temperature at which the open-celled $\mathrm{SiC}$ foams were heated, e.g., $\mathrm{X}=13$ for $1300^{\circ} \mathrm{C}$.

\subsection{Material characterization}

AHPCSB30 was fully characterized in our previous report [33]. High-temperature thermogravimetric analysis (HT-TGA, Setaram Setsys $2400 \mathrm{CS}$ evolution equipment) of the foams prepared at $1000{ }^{\circ} \mathrm{C}$ was performed in flowing argon from 25 to $1500^{\circ} \mathrm{C}$ at a heating rate of 5 ${ }^{\circ} \mathrm{C}$. $\min ^{-1}$ using tungsten crucibles. X-ray diff raction was carried out from 20 to $80^{\circ}$ with a step size of $0.0167^{\circ}$ using a Philips PW 3040/60
X'Pert PRO X-ray diff raction system operating at $30 \mathrm{~mA}$ and $40 \mathrm{kV}$ to identify the crystalline phase assemblage of the samples. Samples were also investigated by SEM (Hitachi S4800) coupled with EDX to assess the morphology of the samples while measuring the $\mathrm{Si}, \mathrm{C}$ and $\mathrm{O}$ content in materials. ICP-OES (Perkin Elmer Optima 7000 DV) was performed at the IUT Montpellier-Sète (France). $\mathrm{N}_{2}$ adsorptiondesorption iso- therms were carried out using a Model Sorptomatic 1900 analyser (Fisons); prior to the analysis samples were degassed overnight at $150^{\circ} \mathrm{C}$. The Brunauer-Emmett-Teller (BET) method was used to cal- culate the specific surface area of samples. A Micromeritics Autopore IV 9500 mercury porosimeter was used to investigate the pore size dis- tribution of the samples. Compression tests were carried out on espe- cially designed cylindrical samples with $10 \mathrm{~mm}$ diameter and $4 \mathrm{~mm}$ height using a universal testing machine (Instron 1121 UTM, Instron Danvers, MA) at a cross head speed of $1 \mathrm{~mm} / \mathrm{min}$; at least three samples were tested for each data point, and values are reported as mean \pm standard deviation. The aging tests of foams including mSiBC30_10 and mSiBC30_13 samples were performed in six micro-autoclaves made of Inconel 600 arranged set-up in an oven at $330^{\circ} \mathrm{C}$ under $140 \mathrm{bar}$ and containing demineralized water with $2.24 \mathrm{ppm}\left(\mathrm{mg}^{-\mathrm{L}^{-1}}\right)$ of lithium and $590 \mathrm{ppm}$ of boron at a pH of 6.8 to reproduce the working condi- tions of a primary loop of coolant [39] (Fig. 2).

In parallel, the microfiltration capacity of $\mathrm{mSiBC30} 10$ samples was tested for $220 \mathrm{~h}$ by using a closed system under 90 bar up to $275^{\circ} \mathrm{C}$, which was based on a filter cascade as illustrated in Fig. 2. The filtration system, as a dead-end filtration process, contained diff erential pressure detectors at each of the three consecutive filters with diff erent porosity ranges $[40,41]$. The mSiBC30_10 samples were considered as the filter 1 with the largest porosity. The foam was inserted in a PTFE ring for sealing before being mounted between two stainless pieces. The system was then set-up in the chamber of the filter 1. The two other filters with lower porosity were commercially available. Such a system allowed for the in-situ measurement of the pressure upstream and downstream from the open-celled SiC foams, during filtration at a flow rate of $40 \mathrm{~mL} \cdot \mathrm{min}^{-1}$ of demineralized water containing ethanolamine ( $3 \mathrm{ppm})$

and ammonia ( $1 \mathrm{ppm}$ ) as well as magnetite particles (around $5 \mu \mathrm{m}$ in diameter and $10 \mathrm{~g}$ of particles for $50 \mathrm{ml}$ of demineralized water), simulating the corrosion products coming from structural materials used in the primary loop of coolant. 


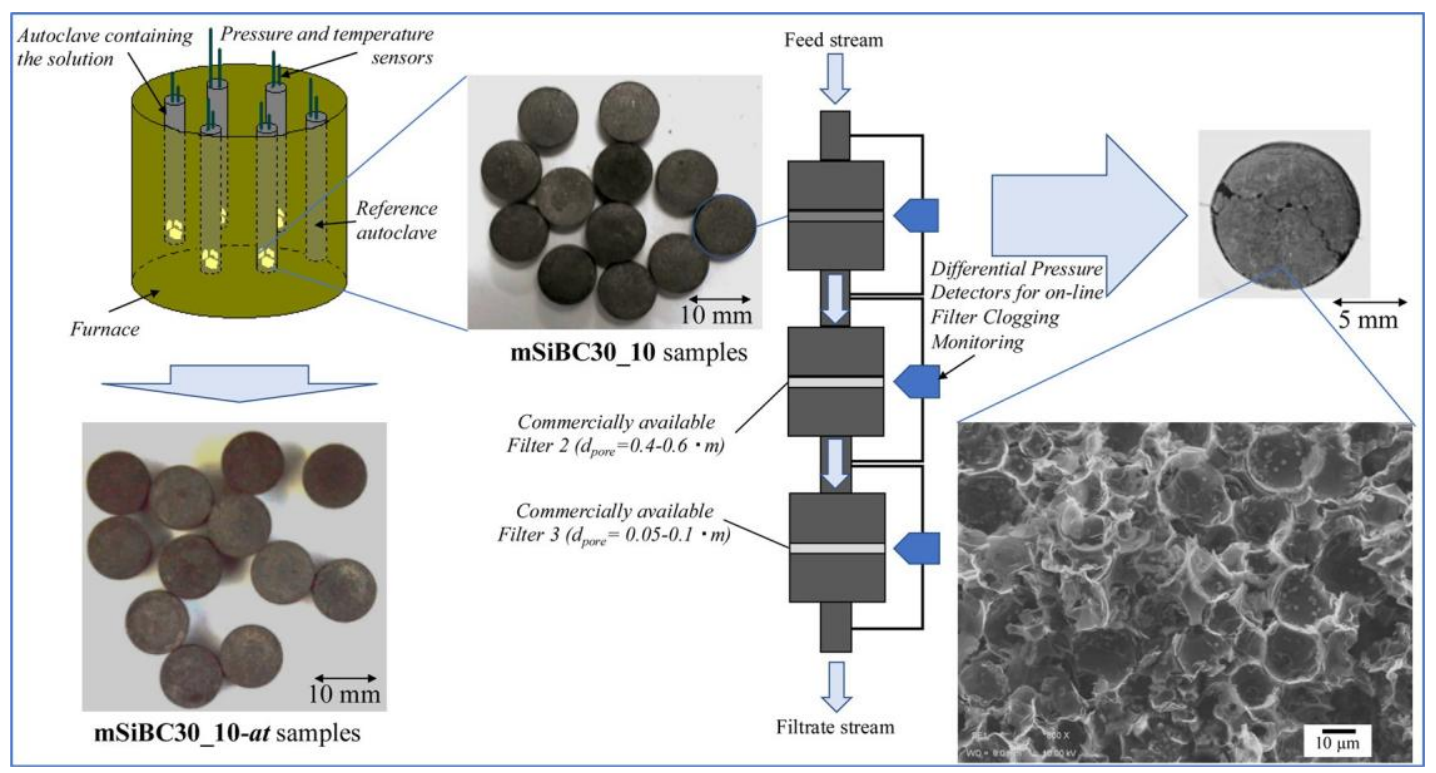

Fig. 2. Schematic representation of the ageing and microfiltration tests performed on a series of mSiBC30_10 samples.

\section{Results and discussion}

\subsection{Design and characterization of open-celled SiC foams}

The modification of AHPCS by BDMS allows adjusting the degree of cross-linking of the derived polymer, i.e., AHPCSB30 for solid-state processing. Thus, AHPCSB30 is a solid compound with a ceramic yield as high as $91 \%$ [33] that could be mixed with $25 \mu \mathrm{m}$ PMMA microbeads as a pore former to form homogeneously mixed powders with controlled AHPCSB30:PMMA weight ratios. Powders could be then warmpressed and pyrolyzed to generate foams. The 20:80 ratio was selected as the most appropriate AHPCSB30:PMMA weight ratio, based on the fact that the corresponding samples did not collapse upon pyrolysis (as observed with samples prepared with $10: 90$ and $15: 85$ wt ratios) while being mechanically stable and presenting a high level of interconnected porosity after pyrolysis (samples prepared with the 30:70 wt ratio did not display a significant level of interconnectivity). The pyrolysis at $1000^{\circ} \mathrm{C}$ produced the $\mathrm{mSiBC} 30 \quad 10$ samples with an empirical formula of $\mathrm{Si}_{1.0} \mathrm{~B}_{0.04} \mathrm{C}_{1.6} \mathrm{O}_{0.18}$. As-obtained samples are $\mathrm{X}$-ray amorphous, based on the presence of diff use SiC diff raction peaks in their powder XRay Diff raction (XRD) pattern, and contain free carbon, as indicated by the chemical composition and the Raman spectrum through the appearance of the D and G bands of free carbon (See Fig. 1SI in ESI). As shown in Fig. 1, as-obtained materials reproduce the monolithic shape of the warm-pressed samples without the presence of any defects or cracks, whereas a volume shrinkage equivalent to $52.6 \%$ occurs (very close to bulk analogs). As shown in the high magnification SEM image (as inset in Fig. 1), the mSiBC30_10 samples display a typical combination of spherical voids with a size controlled by the diameter of the PMMA beads. These macropores, homogeneously distributed within the bulk, contain a large amount of cell windows, aff ording high inter- connectivity among adjacent cells to the foams. In order to better qualify and quantify the macroporosity and pore interconnectivity of in mSiBC30_10 samples, mercury intrusion porosimetry was carried out (Fig. 3).

During $\mathrm{Hg}$ porosimetry experiments, we observed a continuous increase in mercury uptake with the decrease in pore diameter within one intrusion step (i.e., increase of $\mathrm{Hg}$ intrusion pressure), as illustrated through the evolution of the cumulative pore volume versus pore diameter. This indicates a sharpening of the distribution of the cell windows in the samples. As a consequence, the log diff erential intrusion versus diameter, demonstrating the rate-limited filling of the pores by

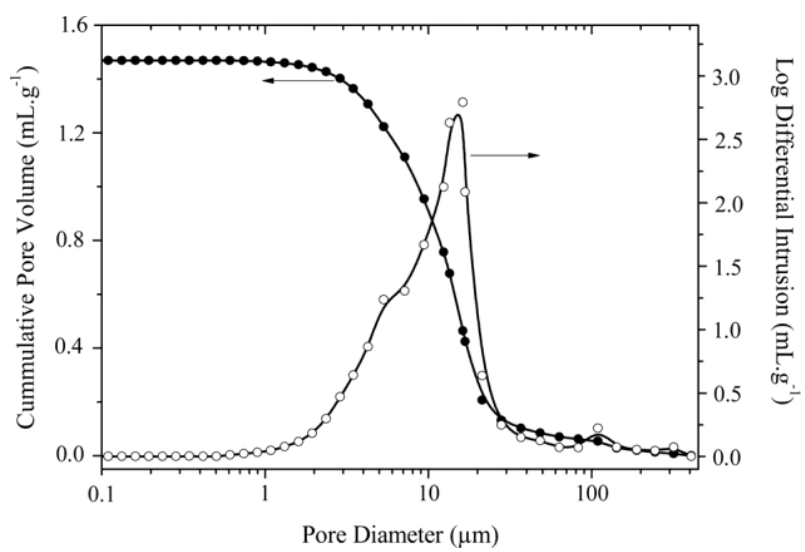

Fig. 3. Macroscopic pore-size distribution obtained by mercury-intrusion porosimetry of the mSiBC30_10 samples.

mercury under pressure, is represented by one signal with a shoulder on the left part from 5 to $7 \mu \mathrm{m}$ allowing to range the size of the windows from 2 to $25 \mu \mathrm{m}$. The mSiBC30_10 samples exhibit a total porosity of $73.4 \mathrm{vol} \%$ and an intrusion volume as high as $1.47 \mathrm{~cm}^{3} \cdot \mathrm{g}^{-1}$. They display a bulk density as low as $0.51 \mathrm{~g} . \mathrm{cm}^{-3}$ and a skeletal density of $1.92 \mathrm{~g} . \mathrm{cm}^{-3}$. We confirmed such data by increasing the diameter of the foams to $20 \mathrm{~mm}$ (See Fig. 2SI in ESI): A total porosity of $77.2 \mathrm{vol} \%$ and an intrusion volume as high as $1.66 \mathrm{~cm}^{3} . \mathrm{g}^{-1}$ have been determined. They display a bulk density as low as $0.47 \mathrm{~g} . \mathrm{cm}^{-3}$ and a skeletal density of $2.04 \mathrm{~g} . \mathrm{cm}^{-3}$. According to the relatively high porosity, an average compressive strength of $3.49 \pm 0.56 \mathrm{MPa}$ was measured. Although it is challenging to speculate on these results, we can consider reports using a similar strategy to prepare foams. Based on an equivalent precursor (polysilazane):PMMA ratio (i.e., 20:80), C. Vakifahmetoglu et al. prepared $\mathrm{Si}(\mathrm{O}) \mathrm{CN}$ foams with an average compressive strength of $5.6 \pm 0.7 \mathrm{MPa}$ for a higher porosity (77.24 vol\%) [23]. SiOC microcellular produced from a silicone resin using the same amount and size of PMMA microbeads had a compression strength, after pyrolysis, of about $5.4 \pm 0.9 \mathrm{MPa}$ [42]. In contrast, using a physical blowing agent, the same authors produced oxygen-free SiCN foams with a porosity of $70.68 \mathrm{vol} \%$ and a flexural strength of $2.89 \pm 1.04 \mathrm{MPa}$. Authors applied the model proposed by Gibson and Ashby [43] to discuss on the compressive strength of their samples, for which the validity of the model is appropriate (relative density lower than 0.3 ). 


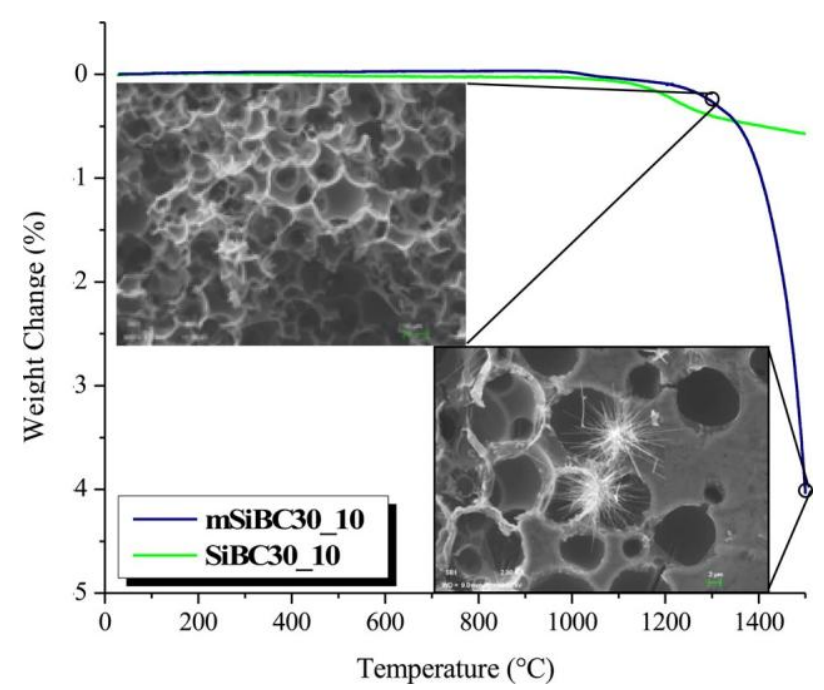

Fig. 4. High temperature TG experiments recorded under argon $\left(5^{\circ} \mathrm{Cmin}^{-1}\right)$ for the SiBC30_10 and mSiBC30_10 samples. SEM images of the mSiBC30_10 sample annealed at $1300^{\circ} \mathrm{C}\left(\mathrm{mSiBC} 30 \_13\right)$ and $1500^{\circ} \mathrm{C}$ (mSiBC30_15) as inset.

In our case, and based on SEM images, it appears that the mSiBC30_10 samples possess a morphology close to SiCN foams produced using a physical blowing agent and made of spheroidal cells with circular interconnecting windows. Thus, we can consider mSiBC30_10 samples as open-celled SiC foams and this is most probably the reason of their lower compressive strength compared to those measured for $\mathrm{Si}$ (O)CN foams using an equivalent precursor:PMMA ratio (i.e., 20:80).

\subsection{High temperature behavior of open-celled SiC foams}

The high temperature behavior of mSiBC30_10 samples was first investigated through high temperature TG experiments up to $1500^{\circ} \mathrm{C}$ in an argon atmosphere (Fig. 4). As a comparison, the TG curve of the bulk analog labelled SiBC30_10, prepared by direct pyrolysis of AHPCSB30 in an argon atmosphere at $1000{ }^{\circ} \mathrm{C}$ was reported [33]. Then, complementary characterization experiments of samples pyrolyzed at different temperatures in the temperature range $1000-1500^{\circ} \mathrm{C}$ were carried out to follow the evolution of the porosity characteristic and the mechanical behavior of open-celled SiC foams at high temperature.

As expected, the mSiBC30_10 samples do not undergo any weight loss after heat-treatment to $1000{ }^{\circ} \mathrm{C}$; temperature at which they were prepared. Then, a two-step weight loss occurs: a first and very small weight loss $(0.25 \%)$ was measured in the temperature range 1000$1300{ }^{\circ} \mathrm{C}$ and a second one, more significant (3.75\%), was then identified from 1300 to $1500{ }^{\circ} \mathrm{C}$. Thus, a total weight loss of $4 \%$ was measured at $1500{ }^{\circ} \mathrm{C}$ for mSiBC30_10 samples. It should be pointed out that the shrinkage upon annealing to $1500{ }^{\circ} \mathrm{C}$ is difficult to quantify because its evolution is very poor. As a comparison, the SiBC30_10 samples display a single weight loss from $1120^{\circ} \mathrm{C}$ to $1500{ }^{\circ} \mathrm{C}$. A total weight loss as low as $0.55 \%$ has been measured at $1500^{\circ} \mathrm{C}$ for the SiBC30_10 samples.

The diff erences in terms of high temperature thermal behavior between both samples are related to both the architecture and composition of the materials. First, it should be pointed out that the mSiBC30_10 samples contain a certain amount of oxygen (5.6 wt\%) whereas the bulk analogs exhibit a very low oxygen content ( $0.3 \mathrm{wt} \%$ ). The boron and carbon contents in the macroporous samples are 0.9 and $35.6 \mathrm{wt} \%$, respectively. These values, especially for boron, are relatively close to those found in the bulk analog [33]. The higher carbon content in the porous samples most probably comes from the presence of carbon residue from decomposition of PMMA. The oxygen intake could be attributed to the combined eff ects of (a) the use of PMMA (its decomposition during the pyrolysis involving release of oxygen-based species that could react with the system which is not yet fully converted into a ceramic), (b) relatively high sensitivity of the preceramic polymer to moisture (during warm pressing, although performed in a glove-box, transfer into the furnace, handling for characterization) [23], and (c) the presence of an open porosity that makes the sample more sensitive to oxidation. In addition, we cannot exclude in both samples the presence of residual hydrogen that is removed above $1000{ }^{\circ} \mathrm{C}$ during the transformation of AHPCSB30 into SiC [33]. Secondly, the mSiBC30_10 samples possess an open and accessible network structure (because of interconnected pores), as demonstrated by SEM images (Fig. 1), that clearly facilitates the release of gaseous species, especially compared to "closed" systems as represented by the bulk analog, i.e., SiBC30_10 samples. Thus, the release of residual hydrogen is most probably associated with the first weight loss identified between 1000 and $1300^{\circ} \mathrm{C}$ for the mSiBC30_10 samples, and shifted to higher temperature, i.e., above $1120^{\circ} \mathrm{C}$, for SiBC30_10 samples. The weight loss observed in $\mathrm{mSiBC30 \_ 10} \mathrm{samples} \mathrm{when} \mathrm{the} \mathrm{temperature} \mathrm{is}$ raised beyond about $1300{ }^{\circ} \mathrm{C}$ could be attributed to the evolution of oxygen-containing gaseous species such as CO and $\mathrm{SiO}[44,45]$. The latter is expected to readily react with free carbon to form stoichiometric SiC by carboreduction reaction at higher temperature, involving $\mathrm{CO}$. To confirm the formation of SiC after annealing to $1500{ }^{\circ} \mathrm{C}$, we observed the evolution of the porous structure of the samples by SEM/ EDS after annealing to $1000^{\circ} \mathrm{C}$ (See Fig. 1 as inset), $1300^{\circ} \mathrm{C}$ and $1500^{\circ} \mathrm{C}$ (Fig. 4 as inset). Whereas the SEM images of $\mathrm{mSiBC30 \_ 13}$ samples, i.e., mSiBC30_10 samples annealed at $1300^{\circ} \mathrm{C}$ (Fig. 4 as inset), do not show any diff erence in terms of pore structure and distribution compared to the mSiBC30_10 samples, we observed the formation of SiC (as con- firmed by EDS) whiskers in the $\mathrm{mSiBC30} 15$ samples, i.e., mSiBC30_10 samples annealed at $1500^{\circ} \mathrm{C}$ (Fig. 4 as inset), highlighting the occur- rence of vapor phase reactions at high temperature, most probably in the temperature range $1300-1500{ }^{\circ} \mathrm{C}$. In such porous samples, the dif- fusion paths for $\mathrm{CO}$ (resulting from the reaction between silicon oxide gases and free carbon) are shorter and hence, formation of stoichio- metric SiC is kinetically favored compared to bulk samples in which no $\mathrm{SiC}$ whiskers were identified after annealing to $1500^{\circ} \mathrm{C}$.

In order to understand the eff ect of the high temperature treatment of open-celled SiC foams on their porosity characteristics, the evolution of the pore architecture of the mSiBC30_10 samples between 1000 and $1500{ }^{\circ} \mathrm{C}$ was firstly assessed at the mesoscopic length scale by nitrogen gas adsorption-desorption measurements at $77^{\circ} \mathrm{K}$ (Fig. 5). Thus, mSiBC30_X $\left(\mathrm{X}=12\left(1200^{\circ} \mathrm{C}\right), 13\left(1300^{\circ} \mathrm{C}\right)\right.$ and 15 $\left.\left(1500^{\circ} \mathrm{C}\right)\right)$ samples

were obtained by annealing treatment of the mSiBC30_10 samples at 1200,1300 and $1500{ }^{\circ} \mathrm{C}$ (a dwelling time of $2 \mathrm{~h}$ was applied at the final temperature).

Based on IUPAC classification $[3,46]$, the adsorption-desorption isotherms of the mSiBC30_10 samples has a type-II shape, characterized by a progressive increase of the adsorbed quantity of nitrogen with the P/Po increase: such an isotherm is in general produced from nonporous or macroporous samples. As a confirmation of the macroporous nature of this sample, a specific BET surface area as low as $1.7 \mathrm{~m}^{2} \cdot \mathrm{g}^{-1}$ was measured, whereas a total pore volume (for pores smaller than $79.61 \mathrm{~nm}$ ) of only $0.0017 \mathrm{~cm}^{3} \mathrm{~g}^{-1}$ was determined from the amount of nitrogen adsorbed at $\mathrm{P} / \mathrm{Po}=0.97$. The horizontal isotherm characteristic of the mSiBC30_12 samples indicates a saturation of the adsorbent. Such isotherms are in general obtained with adsorbents containing micropores. This is confirmed with the relatively fast increase of the adsorbed volume at very low $\mathrm{P} / \mathrm{Po}$, indicating the development of $\mathrm{mi}$ croporosity in this sample. This can be related to the release of dihydrogen from the $\mathrm{mSiBC} 30 \_10$ samples from 1000 to $1200^{\circ} \mathrm{C}$, involving the first weight loss identified in the TG curve depicted in Fig. 4. As a consequence, an increase of the specific BET surface area to $6.7 \mathrm{~m}^{2} \cdot \mathrm{g}^{-1}$ was measured, whereas a total pore volume (for pores smaller than $79.6115 \mathrm{~nm}$ ) of $0.0040 \mathrm{~cm}^{3} \mathrm{~g}^{-1}$ was determined from the amount of nitrogen adsorbed at $\mathrm{P} / \mathrm{Po}=0.97$ in the $\mathrm{mSiBC30 \_ 12}$ samples. The 
specific BET surface area still increased in the mSiBC30_13 samples to 


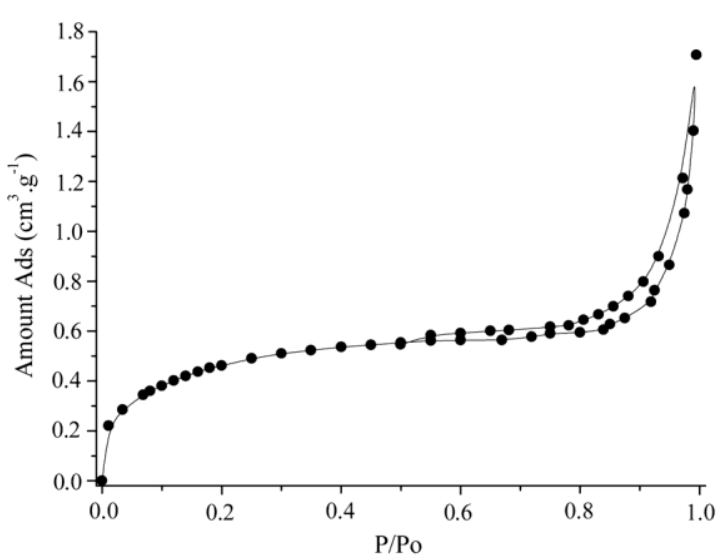

(a)

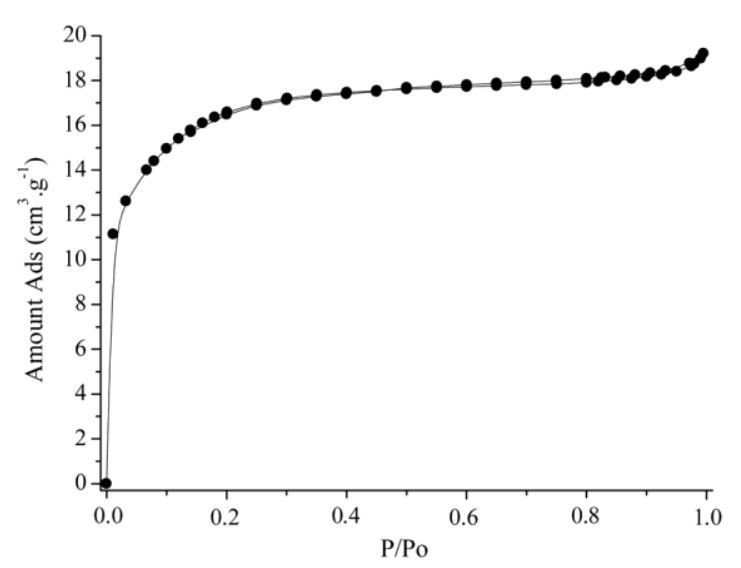

(c)

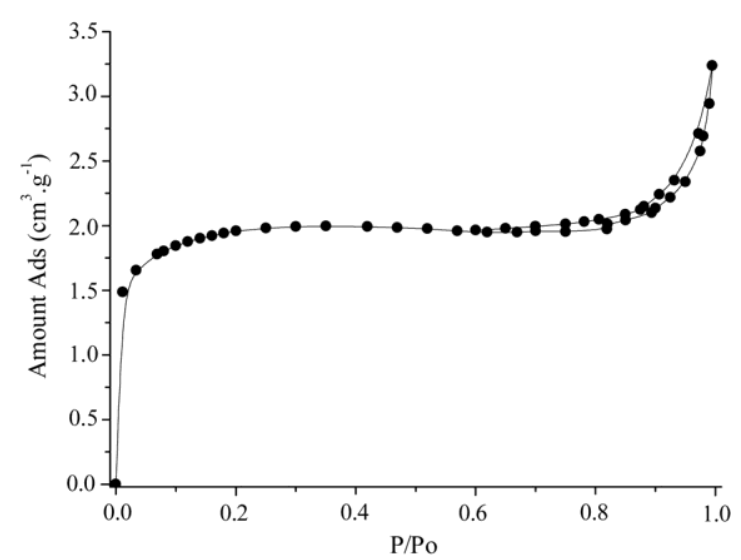

(b)

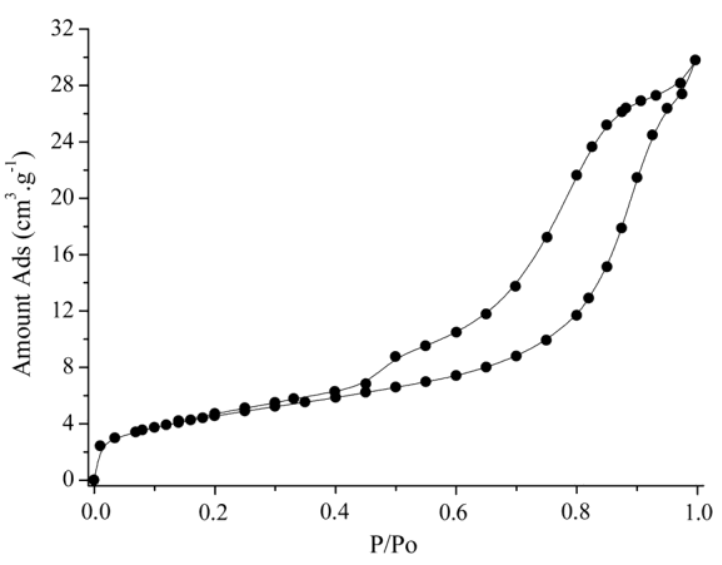

( d)

Fig. 5. $\mathrm{N}_{2}$ adsorption-desorption isotherms of the mSiBC30_10 (a), mSiBC30_12 (b), mSiBC30_13 (c) and mSiBC30_15 (d) samples.

reach a value of $58.44 \mathrm{~m}^{2} \cdot \mathrm{g}^{-1}$, because of the contribution of micropores (fast increase of the adsorbed volume at very low $\mathrm{P} / \mathrm{Po}$ ). To illustrate this, a pore size of $2.93 \mathrm{~nm}$ was computed at the mesoscopic length scale in the mSiBC30_13 samples, whereas it was $20 \mathrm{~nm}$ in the mSiBC30_12 samples. The total pore volume (for pores smaller than 79.6115), determined from the amount of nitrogen adsorbed at $\mathrm{P} /$ Po $=0.97$, increased to $0.029 \mathrm{~cm}^{3} \mathrm{~g}^{-1}$ confirming the formation of a hierarchical porosity within the sample. The profile of the isotherms of the $\mathrm{mSiBC30} 15$ samples shows a $\mathrm{H} 3$-type hysteresis from $\mathrm{P} / \mathrm{Po}=0.4$ to $\mathrm{P} / \mathrm{Po}=1$, which is characteristic of a low degree of pore curvature and non-rigidity of the aggregate structure. Although the BET surface area decreased to $16.9 \mathrm{~m}^{2} \cdot \mathrm{g}^{-1}$, the total pore volume (for pores smaller than $79.6115 \mathrm{~nm}$ ), determined from the amount of nitrogen adsorbed at $\mathrm{P} / \mathrm{Po}=0.97$, still increased to $0.042 \mathrm{~cm}^{3} \mathrm{~g}^{-1}$ most probably because of the increased content of macropores to the detriment of mesopores. We suggested that this was due to the coalescence of micropores and mesopores into macropores. Therefore, the evolution of the pore architecture of the mSiBC30_10 samples between 1000 and $1500^{\circ} \mathrm{C}$, at the mesoscopic length scale, confirms the TG experiments concerning the release of gases from the samples that help to develop the micro- and mesoporosity in open-celled SiC foams at high temperature. Thus, opencelled SiC foams with hierarchical porosity were produced at 1300 and $1500^{\circ} \mathrm{C}$. In contrast, the macroporous volume, measured by $\mathrm{Hg}$ porosimetry, did not change drastically upon annealing to $1500^{\circ} \mathrm{C}$ : it varies from 73.4 vol\% (mSiBC30_10 samples) to 70.5 vol\% (mSiBC30_15 samples). The mSiBC30_13 samples possess a porosity of 71.6 vol $\%$. In the same time, the skeletal density varies from $1.92 \mathrm{~g} . \mathrm{cm}^{-3}$

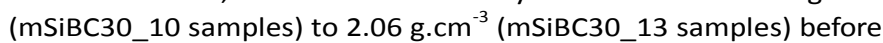
decreasing to $1.54 \mathrm{~g} . \mathrm{cm}^{-3}$ (mSiBC30_15 samples). The mechanical properties of the $\mathrm{mSiBC30} 10$ samples remain stable even after at $1300{ }^{\circ} \mathrm{C}$, i.e., $\mathrm{mSiBC} 30 \_13$ samples, which possess a compression strength of $3.37 \pm 1.86 \mathrm{MPa}$. It decreases to $2.26 \pm 0.49 \mathrm{MPa}$ for the $\mathrm{mSiBC30} 15$ samples that tend to confirm the degradation of opencelled $\mathrm{SiC}$ foams upon annealing above $1300{ }^{\circ} \mathrm{C}$.

Based on the results discussed above, it is reasonable to consider that open-celled $\mathrm{SiC}$ foams are relatively stable even after annealing to $1300{ }^{\circ} \mathrm{C}$. Interestingly, we can tune the porosity of the foams at diff erent length scales through the temperature of annealing: opencelled $\mathrm{SiC}$ foams were produced at $1000{ }^{\circ} \mathrm{C}$ whereas foams with a hierarchical porosity were produced at $1300{ }^{\circ} \mathrm{C}$. In the latter, the microstructural characterization carried out by XRD revealed the presence of distinct

XRD peaks related to the $\beta$-SiC phase at $2 \theta=35.6^{\circ}(111), 60.2^{\circ}(220)$, and $72.1^{\circ}$ (311) (mSiBC30_13 samples; See Fig. 2SI in ESI), which were poorly resolved in the XRD pattern of the $\mathrm{mSiBC30} 10$ samples (See Fig. 1SIa in ESI). The crystal growth also followed an increasing trend with processing temperature, according to the calculation of the average crystallite size by applying the Scherrer equation to the (111) peak, which showed an increase of the grain size from $0.8 \mathrm{~nm}$ for the 
mSiBC30_10 samples to $2.3 \mathrm{~nm}$ for the mSiBC30_13 samples.

\subsection{Ageing and microfiltration tests of open-celled SiC foams}

Both mSiBC30_10 and mSiBC30_13 samples were used for investigating the ageing of open-celled $\mathrm{SiC}$ foams and their chemical stability in the working conditions of a primary coolant loop in a Pressurized Water Reactor (PWR). In parallel, the microfiltration capacity of foams toward colloids was investigated.

The primary loop of coolant, flowing through the reactor core at very high pressure to remain a liquid, prevents water from boiling within the reactor. It is comprised of a solution made of boric acid and lithium hydroxide to maintain the reactor coolant at an alkaline value. Because the primary loop is made of nickel and zirconium alloys as well as stainless steels, corrosion occurs. The corrosion products coming from the corrosion of the structure materials in contact with the primary coolant are in the form of soluble, colloidal or particulate compounds, which are transported by the primary coolant to the core where they become activated and redistributed out of the core surfaces. The deposits as radionuclides generate dose rate mainly at the bottom of the pressurized reaction vessel and on the surface of the steam generator tubes [47]. To limit the formation of radionuclides and reduce the dose rates, porous ceramics could be employed to separate such radionuclides from the solution. However, porous ceramics should be stable in the conditions imposed by the primary loop. In the present work, ageing tests were performed in a static autoclave under 140 bar at $330^{\circ} \mathrm{C}$ in demineralized water containing $2.24 \mathrm{ppm}\left(\mathrm{mg} \cdot \mathrm{L}^{-1}\right)$ of lithium and $590 \mathrm{ppm}$ of boron (both measured by ICP), at a pH of 6.8 , to reproduce the working conditions of a primary loop of coolant. Tests were carried out on a series of several pieces representative of the mSiBC30_10 samples (See Fig. 2). After the tests, samples labelled mSiBC30_10-at (at for ageing tests) were characterized by XRD, Hg porosimetry, SEM, EDX, and the solution after ageing was analyzed by ICP to measure the Si and B contents.

Samples were weighed before and after the tests according to this procedure: cleaning with demineralized water under ultra-sonication for $5 \mathrm{~min}$, followed by drying in an oven at $100{ }^{\circ} \mathrm{C}$ for $24 \mathrm{~h}$ then in a desiccator for $12 \mathrm{~h}$. The mSiBC30_10 samples undergo a weight loss of $6.8 \%$ after the ageing test, suggesting that the samples degrade under the imposed conditions. The solutions in which the samples were immersed possess a silicon (Si) content of $551 \mathrm{mg} \mathrm{L}^{-1}$ (there was no $\mathrm{Si}$ in the solution before tests), whereas the boron (B) content is 728 $\mathrm{mg} \mathrm{L}^{-1}\left(590 \mathrm{mg} \mathrm{L}^{-1}\right.$ in the solution before tests) and the $\mathrm{pH}$ decreases from 6.8 to 4.3 after the ageing test. Therefore, we could infer that the mSiBC30_10 samples released silica, which is known to be an oxide acid, and boric acid. Although the $\mathrm{mSiBC30 \_ 10} \mathrm{samples} \mathrm{were} \mathrm{X-}$ ray amorphous (See Fig. 1SIa in ESI), it seems that a further "amorphization" process occurred after ageing tests in the mSiBC30_10-at samples, as shown by the broader (111) and (220) XRD peaks of the $\beta$ SiC phase (See ESI, Fig. 1SIa). SEM-EDS investigations showed the presence of spheres (1-2 microns in diameter) at the surface of the mSiBC30_10-at samples (Fig. 6b), which were not present in the mSiBC30_10 samples (Fig. 6a).

An O content of 57.8 at\%, a Si content of 37.6 at\% and a C content of 4.6 at\% was measured by focusing in the area of spheres by EDX, whereas the part free of spheres (the bulk) had an O content of 12.9 at $\%$, a Si content of 33.1 at\% and a C content of 53.9 at\%. Therefore, we suggested the formation of silica spheres at the surface of the samples that inherently lead to the "amorphization" of the mSiBC30_10-at samples as shown by XRD. It is important to mention that those spheres were not observed when using $\mathrm{Li}$ - and $\mathrm{B}$-free demineralized water during the ageing tests. Therefore, this clearly confirms that silica spheres formed because of the presence of $\mathrm{Li}$ and $\mathrm{B}$ within the solution simulating the primary loop of coolant. As a result of the formation of silica spheres, Hg porosimetry analysis (See Fig. 2 and Fig. 3SI in ESI) showed a distinct shift of the cell windows toward lower sizes in the range 1-6 $\mu \mathrm{m}$. Interestingly, the degradation did not aff ect the microfiltration capacity of the foams, since the latter were able to trap magnetite particles present in demineralized water without pressure drop during tests for $220 \mathrm{~h}$. It should be mentioned here that we did not use a solution made of $L i$ and $B$ in order to be able to distinguish magnetite particles (and iron oxide) from silica spheres deposited on the foams by SEM (See Fig. 2). As shown in Fig. 2, a crack appeared along the foams during the removal of the foams from the PTFE ring. However, we can consider that the strength of the foams is suffi ciently high to withstand the conditions imposed by the application.

Because of their porosity characteristics and mechanical properties comparable to those of the $\mathrm{mSiBC} 30$ 10 samples, the stability of the mSiBC30_13 samples was investigated in the same conditions. Interestingly, "amorphization" did not occur in the mSiBC30_13-at samples (See ESI, Fig. 4SI), which could be related to the lower presence of silica sphere at the surface of the sample (See Fig. $6 \mathrm{c}$ (before ageing tests) and $d$ (after ageing tests)). Furthermore, it appeared that the mSiBC30_13 samples release a significantly lower content of Si (255 $\left.\mathrm{mg} \mathrm{L}^{-1}\right)$, whereas the boron content released is similar (773 $\left.\mathrm{mg} \mathrm{L}^{-1}\right)$. This could be explained by the higher degree of crystallization of the mSiBC30_13 samples, that improved its chemical stability. Because of the lower release of $\mathrm{Si}$ as silica, the $\mathrm{pH}$ of the solution was measured to be 5.3. Although the pore junction size was also shifted to lower size from the mSiBC30_13 samples to the mSiBC30_13at samples (See Fig. 3SI in ESI), it had a smaller diff erence compared to the mSiBC30_10 and mSiBC30_10-at samples. Therefore, we may infer that open-celled $\mathrm{SiC}$ foams prepared at $1300{ }^{\circ} \mathrm{C}$ display a higher stabi- lity in harsh environment compared to those prepared at 1000 ${ }^{\circ} \mathrm{C}$, and could withstand the harsh conditions imposed by the primary loop of coolant in PWR.

\section{Conclusion}

Open-Celled silicon carbide ( $\mathrm{SiC}$ ) foams with an interconnected porosity of 73.4 vol\% were prepared from a mixture of boron-modified polycarbosilane and poly(methymetacrylate) (PMMA) microbeads $(25 \mu \mathrm{m})$ sacrificial fillers in a 20:80 ratio. The boron-modified polycarbosilane was synthesized through the reaction between allylhydridopolycarbosilane (AHPCS) and borane dimethylsulfide (BDMS) according to a controlled $\mathrm{Si}: \mathrm{B}$ ratio of 30 . It allowed to significantly reduce its processing temperature compared to thermally crosslinked AHPCS. Thus, warm-pressing of the powder mixture was performed at a temperature as low as $120^{\circ} \mathrm{C}$ and the green body was then pyrolyzed at $1000^{\circ} \mathrm{C}$ under argon. The resulting highly porous components were analyzed in detail at the mesoscopic and macroscopic length scales, and their structural stability as well as compressive strength was investigated. Open-celled SiC foams combined a low density with a compressive strength of $3.49 \pm 0.56 \mathrm{MPa}$ and a thermostructural and mechanical stability that can be extended up to $1300^{\circ} \mathrm{C}$, temperature at which a single-step weight loss continuously occurred up to $1500{ }^{\circ} \mathrm{C}$ without losing the monolithic structure. It was attributed to the evolution of oxygen-containing gaseous species such as $\mathrm{CO}$ and $\mathrm{SiO}$. As a consequence of the release of gaseous species, the BET SSA of foams increased in the temperature range $1000-1500^{\circ} \mathrm{C}$ to form open-celled $\mathrm{SiC}$ foams with a hierarchical porosity at 1300 and $1500^{\circ} \mathrm{C}$. Ageing and microfiltration tests in the condition of a primary loop of coolant in a Pressurized Water Reactor (PWR) showed that open-celled SiC foams were able to retain particles with diameter around $5 \mu \mathrm{m}$ without degradation of the performance of filtration, but those prepared at $1300{ }^{\circ} \mathrm{C}$ demonstrated a higher chemical stability than open-celled SiC foams prepared at $1000^{\circ} \mathrm{C}$ in the tested conditions.

\section{Acknowledgements}

Dr. Samuel Bernard and Prof. Philippe Miele gratefully acknowledges AREVA NP and ANRT for their financial support of the PhD thesis 


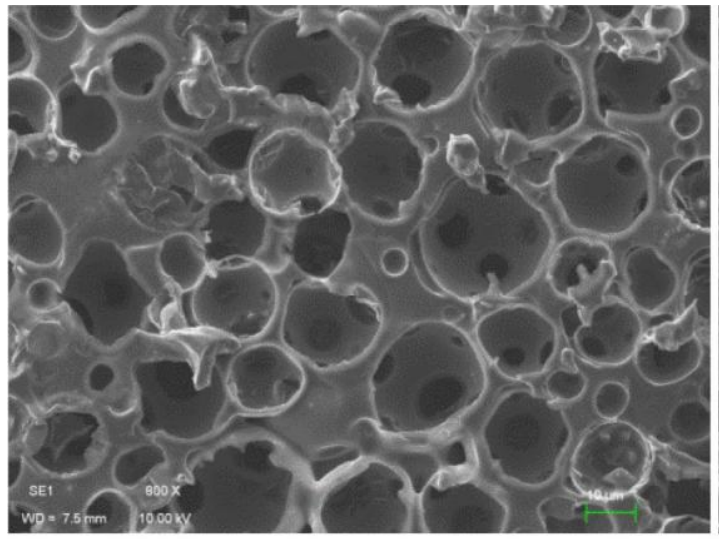

(a)

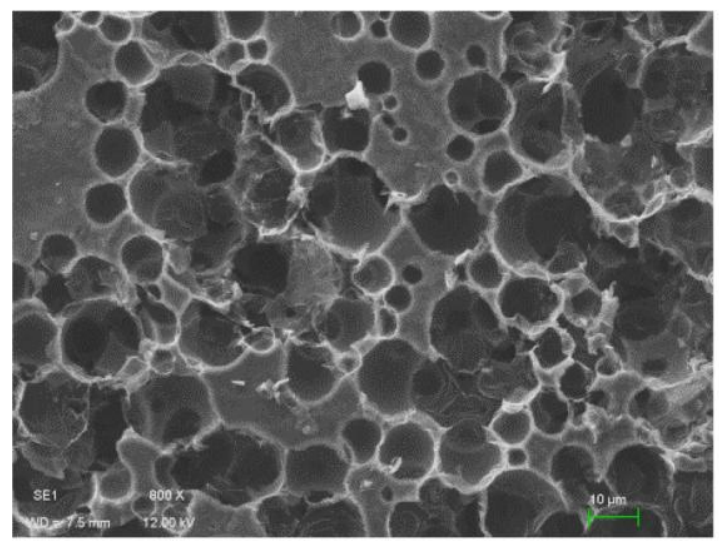

(c)

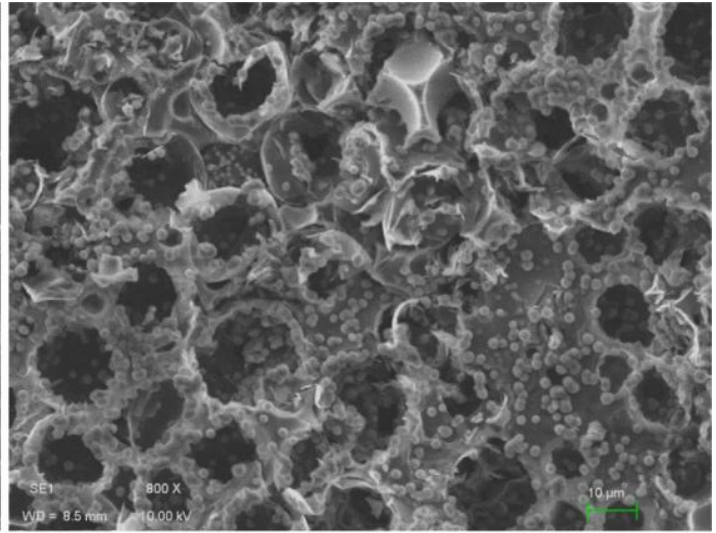

(b)

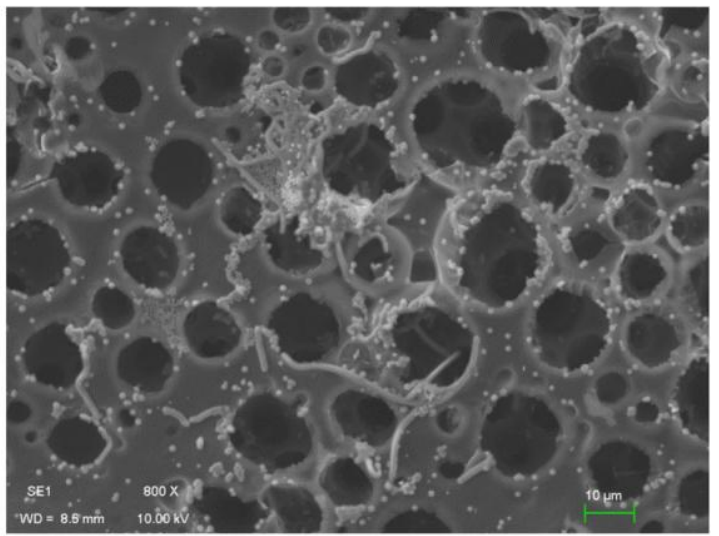

( d)

Fig. 6. Low magnification SEM image of the mSiBC30_10 and mSiBC30_13 samples before $(a, c)$ and after ageing and microfiltration tests (b,d).

of Charlotte Durif. Dr. Samuel Bernard also acknowledges the funding agency Agence Nationale de la Recherche (ANR) for supporting this work through the Polyceramem project (Project number ANR-13-BS08-009) and the Carapass project (Project number ANR-16-CE08-0026). Dr. Samuel Bernard would like to thank IUT Montpellier-Sète (France) for ICP-OES experiments. Dr. Samuel Bernard, Prof. Anne Leriche and Prof. Philippe Miele thank the Région 'Nord-Pas-De-Calais' for the financial support of the PhD thesis of Mélanie Wynn.

\section{References}

[1] M.M. Dubinin, The potential theory of adsorption of gases and vapors for adsorbents with energetically nonuniform surfaces, Chem. Rev. 60 (1960) 235-241.

[2] D.H. Everett, IUPAC, Manual of symbol and terminology for physico-chemical quantities and units, appendix, definitions, terminology and symbols in colloid and surface chemistry, Part I, Pure Appl. Chem. 31 (1972) 579-638.

[3] K.S.W. Sing, D.H. Everett, R.W. Haul, L. Moscou, R.A. Pierotti, J. Rouquerol, T. Siemieniewska, Reporting physisorption data for gas/solid systems with special reference to the determination of surface area and porosity, Pure Appl. Chem. 57 (1985) 603-619.

[4] A. Lale, M. Schmidt, M.D. Mallmann, A.V.A. Bezerra, E. Diz Acosta, R.A.F. Machado, U.B. Demirci, S. Bernard, Polymer-derived ceramics with engineered mesoporosity: from design to application in catalysis, Surf. Coat. Technol. 350 (2018) 569-586.

[5] F. Sandra, O. Majoulet, M. Depardieu, Z. Mouline, A. Viard, G. Vignoles,
Y. Iwamoto, P. Miele, R. Backov, S. Bernard, Polymer-derived silicoboron carbonitride foams for $\mathrm{CO}_{2}$ capture: from design to application as scaff olds for the in-situ growth of metal-organic frameworks, Chem. Eur. J. 22 (2016) 8346-8357.

[6] O. Majoulet, F. Sandra, M.C. Bechelany, G. Bonnefont, G. Fantozzi, L. Joly-Pottuz, A. Malchere, S. Bernard, P. Miele, Silicon-boron-carbon-nitrogen monoliths with high, interconnected and hierarchical porosity, J. Mater. Chem. A 1 (2013) 1099111000.

[7] U. Scheithauer, F. Kerber, A. Füssel, S. Holtzhausen, W. Beckert, E. Schwarzer, S. Weingarten, A. Michaelis, Alternative process routes to manufacture porous ceramics-opportunities and challenges, Materials 12 (2019) 663-680.

[8] F. Sandra, A. Ballestero, V.L. NGuyen, M.N. Tsampas, P. Vernoux, C. Balan, Y. Iwamoto, U.B. Demirci, P. Miele, S. Bernard, Silicon carbide-based membranes with high filtration effi ciency, durability and catalytic activity for $\mathrm{CO} / \mathrm{HC}$ oxidation and soot combustion, J. Membr. Sci. 501 (2016) 79-92.

[9] P. Colombo, G. Mera, R. Riedel, G.D. Soraru, Polymer-derived ceramics: 40 years of research and innovation in advanced ceramics, J. Am. Ceram. Soc. 93 (2010) 18051837.

[10] G. Mera, M. Gallei, S. Bernard, E. Ionescu, Ceramic nanocomposites from tailormade preceramic polymers, Nanomaterials 5 (2015) 468-540.

[11] A. Viard, D. Fonblanc, D. Lopez-Ferber, M. Schmidt, A. Lale, C. Durif, M. Balestrat, F. Rossignol, M. Weinmann, R. Riedel, S. Bernard, Polymer derived Si-B-C-N ceramics: 30 years of research, Adv. Eng. Mater. 20 (2018) 1800360-1800371.

[12] H. Termoss, B. Toury, S. Payan, A. Brioude, S. Bernard, D. Cornu, S. Vallette, S. Benayoun, P. Miele, Preparation of boron nitride-based coatings on metallic substrates via infrared irradiation of dip-coated polyborazylene, J. Mater. Chem. 19 (2009) 2671-2674.

[13] E. lonescu, S. Bernard, R. Lucas, P. Kroll, S. Ushakov, A. Navrotsky, R. Riedel, Ultrahigh temperature ceramics (UHTCs) and related materials - syntheses from polymeric precursors and energetics, Adv. Eng. Mater. (2019), https://doi.org/10. 1002/adem.201900269.

[14] E. Bernardo, L. Fiocco, G. Parcianello, E. Storti, P. Colombo, Advanced ceramics from preceramic polymers modified at the nano-scale: a review, Materials 7 (2014) 1927-1956.

[15] A. Viard, P. Miele, S. Bernard, Polymer-derived ceramics route toward SiCN and SiBCN fibers: from chemistry of polycarbosilazanes to the design and characterization of ceramic fibers, J. Ceram. Soc. Jp 124 (2016) 967-980. 
[16] G. Barroso, Q. Li, R.K. Bordia, G. Motz, Polymeric and ceramic silicon-based coatings - a review, J. Mater. Chem. A 7 (2019) 1936-1963.

[17] S. Bernard, P. Miele, Polymer-derived boron nitride: a review on the chemistry, shaping and ceramic conversion of borazine derivatives, Materials 7 (2014) 7436-7459.

[18] P. Colombo, Engineering porosity in polymer-derived ceramics, J. Eur. Ceram. Soc. 28 (2008) 1389-1395.

[19] Y. Shi, Y. Wan, D. Zhao, Ordered mesoporous non-oxide materials, Chem. Soc. Rev. 40 (2011) 3854-3878.

[20] A. Lale, A. Wasan, R. Kumar, P. Miele, U.B. Demirci, S. Bernard, Organosilicon polymer-derived mesoporous 3D silicon carbide, carbonitride and nitride structures as platinum supports for hydrogen generation by hydrolysis of sodium borohydride, Int. J. Hydrogen Energy 4 (2016) 15477-15488.

[21] L. Borchardt, C. Hoff mann, M. Oschatz, L. Mammitzsch, U. Patasch, M. Herrmann, S. Kaskel, Preparation and application of cellular and nanoporous carbides, Chem. Soc. Rev. 41 (2012) 5053-5067.

[22] C. Vakifahmetoglu, D. Zeydanli, P. Colombo, Porous polymer derived ceramics, Mater. Sci. Eng. R 106 (2016) 1-30.

[23] C. Vakifahmetoglu, I. Menapace, A. Hirsch, L. Biasetto, R. Hauser, R. Riedel, P. Colombo, Highly porous macro- and micro-cellular ceramics from a polysilazane precursor, Ceram. Int. 35 (2009) 3281-3290.

[24] T. Schmalz, J.M. Hausherr, W. Müller, T. Kraus, W. Krenkel, R. Kempe, G. Motz, Analysis of polyethylene-particle filler SiCN precursor and the resulting porous ceramics with emphasis on using micro computed tomography, J. Ceram. Soc. Jp. 119 (2011) 477-482.

[25] T. Konegger, C.-C. Tsai, H. Peterlik, S.E. Creager, R.K. Bordia, Asymmetric polysilazane-derived ceramic structures with multiscalar porosity for membrane applications, Microporous Mesoporous Mater. 232 (2016) 196-204.

[26] T. Konegger, R. Patidar, R.K. Bordia, A novel processing approach for free-standing porous non-oxide ceramic supports from polycarbosilane and polysilazane precursors, J. Eur. Ceram. Soc. 35 (2015) 2679-2683.

[27] S. Yajima, J. Hayashi, M. Omori, Continuous silicon carbide fiber of high tensile strength, Chem. Lett. 4 (1975) 931-934.

[28] S. Yajima, J. Hayashi, M. Omori, K. Okamura, Development of a silicon carbide fibre with high tensile strength, Nature 261 (1976) 683-685.

[29] C. K. Whitmarsh and L. V. Interrante, Carbosilane polymer precursors to silicon carbide ceramics, U.S. Patent No. 5,153,295, October 6: 1992.

[30] Starfire Systems, Inc., $87725^{\text {th }}$ St., Watervliet, NY, 12189.

[31] M. Kotani, K. Nishiyabu, S. Matsuzaki, S. Tanaka, Processing of polymer-derived porous SiC body using allylhydridopolycarbosilane (AHPCS) and PMMA microbeads, J. Ceram. Soc. Jp. 119 (2011) 563-569.

[32] S. Kaur, R. Riedel, E. Ionescu, Pressureless fabrication of dense monolithic SiC ceramics from a polycarbosilane, J. Eur. Ceram. Soc. 34 (2014) 3571-3578.
M. Schmidt, C. Durif, E. Diz Acosta, C. Salameh, H. Plaisantin, P. Miele, R. Backov, R. Machado, C. Gervais, J.G. Alauzun, G. Chollon, S. Bernard, Molecular-level processing of Si-(B)-C materials with tailored nano/microstructures, Chem. Eur. J. 23 (2017) 17103-17117.

[34] M.C. Bechelany, V. Proust, C. Gervais, R. Ghisleni, S. Bernard, P. Miele, In-situ controlled growth of titanium nitride in amorphous silicon nitride: a general route toward bulk non-oxide nitride nanocomposites with very high hardness, Adv. Mater. 26 (2014) 6548-6553.

[35] M.C. Bechelany, V. Proust, A. Lale, P. Miele, S. Malo, C. Gervais, S. Bernard, Nanocomposites through chemistry of single-source precursors: understanding the role of chemistry behind the design of monolith-type nanostructured titanium nitride/silicon nitride, Chem. Eur. J. 23 (2017) 832-845.

[36] A. Viard, D. Fonblanc, M. Schmidt, A. Lale, C. Salameh, A. Soleilhavoup, M. Wynn, P. Champagne, S. Cerneaux, F. Babonneau, G. Chollon, F. Rossignol, C. Gervais, S. Bernard, Molecular chemistry and engineering of boron-modified polyorganosilazanes as new processable and functional SiBCN precursors, Chem. Eur. J. 23 (2017) 9076.

[37] D. Fonblanc, D. Lopez-Ferber, M. Wynn, A. Lale, A. Soleilhavoup, A. Leriche Y. Iwamoto, F. Rossignol, C. Gervais, S. Bernard, Crosslinking chemistry of poly (vinylmethyl-co-methyl)silazanes toward low-temperature formable preceramic polymers as precursors of functional aluminium-modified Si-C-N ceramics, Dalton Trans. 47 (2018) 14580-14593.

[38] L. Stobierski, A. Gubernat, Sintering of silicon carbide II. Eff ect of boron, Ceram. Int. 29 (2003) 355-361.

[39] D. Bourdet, Essais de capsules en four, DQITC-F 039 (2012).

[40] R. Geier, Initial Operation of High Temperature Colloid Catcher with Kurt Microloop at AREVA Technical Center in Le Creusot, ReportAREVA PTCC-G/2013/ en/0203, (2013).

[41] R. Lehr, Test Stage of High Temperature Colloid Catcher with KURT Micro Loop at AREVA Technical Center in Le Creusot, Report AREVA PTCC-G/2013/en, (2013).

[42] P. Colombo, E. Bernardo, L. Biasetto, Novel microcellular ceramics from a silicon resin, J. Am. Ceram. Soc. 87 (2004) 152-154.

[43] L.J. Gibson, M.F. Ashby, Cellular Solids, Structure and Properties, Cambridge University Press, UK, 1999.

[44] S.M. Johnson, R.D. Brittain, R.H. Lamoreaux, D.J. Rowcliff e, Degradation me- chanisms of silicon carbide fibers, J. Am. Ceram. Soc. 71 (1988) 132135.

[45] K.M. Prewo, J.J. Brennan, Silicon carbide yarn reinforced glass matrix composites, J. Mater. Sci. 17 (1982) 1201-1206.

[46] D.H. Everett, IUPAC, manual of symbols and terminology for physicochemical quantities and units, appendix II: definitions, terminology and symbols in colloid and surface chemistry, Pure Appl. Chem. 31 (1972) 579-638.

[47] P. Beslu, G. Frejaville, P. Jeanson, Occupation radiation exposure at French power plants: measurement and Prediction, Nucl. Technol. 44 (1979) 84-90. 